\title{
A laboratory scale approach to wettability restoration in chalk core samples
}

\author{
Jaspreet S. Sachdeva ${ }^{1,2}$, Edison A. Sripal ${ }^{3}$, Anders Nermoen ${ }^{1,2,4}$, Reidar I. Korsnes ${ }^{1,2}$, Merete V. Madland ${ }^{1,2}$, Lesley A. \\ James $^{3, *}$ \\ ${ }^{1}$ The National IOR Centre of Norway \\ ${ }^{2}$ University of Stavanger \\ ${ }^{3}$ Department of Process Engineering, Memorial University of Newfoundland \\ ${ }^{4}$ International Research Institute of Stavanger
}

\begin{abstract}
Wettability in chalk has been studied comprehensively to understand fluid flow mechanisms impacting coreflooding experiments. Wettability becomes paramount in understanding the parameters influencing chalk-fluid interactions. The main objective of this work is to evaluate as to which degree the wettability in chalk core samples can be controlled in the laboratory. Kansas chalk samples saturated with brine $(1.1 \mathrm{M} / 64284 \mathrm{ppm} \mathrm{NaCl})$ and an oil mixture $(60 \%-40 \%$ by volume of Heidrun oil and heptane) were aged at a constant temperature of $90 \mathrm{oC}$ with aging time as the laboratory control variable. A multimodal method incorporating contact angle measurements, wettability index via USBM test, and SEM-MLA analysis was applied in evaluating wettability. A systematic approach was applied with the three different methods to quantify the degree of uncertainty linked to a) wettability estimation and b) the aging procedure to control wettability alteration of Kansas chalk. With a comprehensive suite of samples, we were successfully able to alter the wettability of chalk cores.
\end{abstract}

\section{Introduction}

Wettability is the tendency of one fluid to spread on, or adhere to, a solid surface in the presence of another immiscible fluid. Wettability is of paramount importance in oil recovery from low permeability chalk as it controls the flow and distribution of fluids [1]. In the past, numerous studies have indicated a number of factors influencing wettability including the composition of oil, rock mineralogy, fluid saturation, brine composition, temperature, and time of aging [2]. Although carbonate reservoirs tend to be intermediate to strongly oil wet, in the laboratory restoration to oil wet characteristics is fraught with uncertainties [3].

One of the simplest experimental control variables is the aging time. Anderson [2] indicated that 1000 hours (40 days) of aging at reservoir temperature is sufficient for wettability equilibrium for sandstones. In order to ensure that brine chemistry are not ignored during the aging process it is important to saturate the core with brine prior to any flooding of oil.

Wettability can be quantified using contact angle measurements of a drop placed on top of the surface and/or the USBM method (United States Bureau of Mines). For a reservoir rock to be termed oil wet, the contact angle in an oil-brine-rock system should be greater than $105^{\circ}[2,4,5]$, or the wettability index for the USBM method to be close to -1 , calculated from drainage and imbibition capillary pressure vs saturation curves. USBM method is albeit limited to lower capillary pressure in Chalks [7] which is often compensated using porous plate method. Alternatively, a desaturation technique [6] was applied in tight carbonates to attain water saturation level of $<1$. Robin et al. [6] developed a qualitative description of how to differentiate between oil wet and water wet capillary pressure curves. In addition to the contact angle and USBM methods, Scanning Electron Microscopy (SEM) analyses using Cryo Scanning Electron Microscope (Cryo-SEM) and Environmental Scanning Electron Microscope (ESEM) methods [6,7] have been used to determine wettability in rocks and packed glass beads saturated with reservoir fluids. These analyses had uncertainties as it often compromised the sample integrity due to extreme changes in the physical state because of cooling and polishing. In a newly developed method [8], SEM-MLA (Mineral Liberation Analysis) has been applied by testing the samples without any changes to their physical state.

In this paper we try to determine the threshold duration beyond which the aging does not change the wetting state of outcrop chalk. After aging the chalk cores at high temperature for varying periods of time, wettability determination was performed using contact angle measurements, USBM method and SEM-MLA analysis. Specifically, the study was carried out on outcrop chalk samples as laboratory core flooding and SCAL experiments are routinely performed on core samples from restored state [9]. Similar work had been carried out

* corresponding author: 1james@mun.ca 
previously on Rørdal chalk samples [1] wherein the chalk samples were submerged into crude oil for wettability alteration, and then after aging the crude oil was flushed out by decahydronapthalene, which subsequently was flushed out by decane for imbibition tests. Graue et al. [1] reported that a stable wettability was obtained for cores aged more than 14 days using a different set of fluids.

\section{Experimental methodology}

\subsection{Porous Medium}

The porous media used for this work was outcrop chalk from Kansas, from the Niobrara formation, Fort Hays Member, USA (Late Cretaceous). The Kansas chalk used here displayed a permeability ranging from 1.90 to 2.10 $\mathrm{mD}$, and a porosity ranging from 36.93 to $38.57 \%$. Its carbonate content is approx. 95-97\%, the Biot coefficient is 0.91 and the induration is $\mathrm{H} 3[12,13]$, which imply that Kansas chalk is partially cemented compared to other high porous chalks.

\subsection{Fluids}

The physical properties of the $1.1 \mathrm{M} \mathrm{NaCl}$-brine used to determine the saturation porosity, brine-permeability, and for initial saturation are presented in Table 1. Heidrun (offshore Norway) dead crude oil with $6 \mathrm{cP}$ viscosity and $858 \mathrm{~kg} / \mathrm{m} 3$ density was mixed with n-heptane $(60 \%-40 \%$ by volume) and used as the non-wetting phase. The total acid number (TAN) of the Heidrun crude oil was analyzed and found to be $2.82 \mathrm{mg} \mathrm{KOH} / \mathrm{g}$ (reported to be $3 \mathrm{mg}$ $\mathrm{KOH} / \mathrm{g}$ in [12]), while the mixture obtained an acid number of $2.12 \mathrm{mg} \mathrm{KOH} / \mathrm{g}$ using potentiometric titration method. The oil mixture was filtered ( $5 \mu \mathrm{m}$ filter paper) and degassed by vacuuming for 48 hours to prevent gas production during the drainage. The physical properties of Heidrun crude oil are tabulated in Table 2. The composition of the oil mixture was analyzed using Agilent 7890A Gas Chromatograph with Simulated Distillation (SIMDIS) system (see Table 3).
Table 1. Composition and properties of brine at $25^{\circ} \mathrm{C}$

\begin{tabular}{|c|c|c|c|}
\hline $\begin{array}{c}\text { Brine Salinity } \\
\text { (ppm) }\end{array}$ & $\begin{array}{c}\text { Density } \\
\left(\mathbf{k g} / \mathbf{m}^{\mathbf{3}}\right)\end{array}$ & $\begin{array}{c}\text { Viscosity } \\
\mathbf{( c P )}\end{array}$ & $\begin{array}{c}\text { IFT with oil } \\
\mathbf{( N m} / \mathbf{m})\end{array}$ \\
\hline 64,284 & 1060 & 1.05 & 70.8 \\
\hline
\end{tabular}

Table 2. Properties of Heidrun Crude oil at $25^{\circ} \mathrm{C}$

\begin{tabular}{|c|c|c|c|c|}
\hline Color & $\begin{array}{c}\text { Density } \\
\left(\mathbf{k g} / \mathbf{m}^{\mathbf{3}}\right)\end{array}$ & $\begin{array}{c}\text { Viscosity } \\
\mathbf{( c P )}\end{array}$ & $\begin{array}{c}\text { TAN } \\
\mathbf{( m g} \\
\mathbf{K O H} / \mathbf{g})\end{array}$ & $\begin{array}{c}\text { Asphalte } \\
\text { ne } \\
\text { content } \\
(\mathbf{\%})\end{array}$ \\
\hline $\begin{array}{c}\text { Light } \\
\text { brown }\end{array}$ & 858 & 6 & 2.82 & $<1$ \\
\hline
\end{tabular}

Table 3. Composition of the $60-40$ Heidrun/Heptane oil mixture from GC-analyses

\begin{tabular}{|c|c|c|c|}
\hline Component & $\begin{array}{c}\text { Mass } \\
\text { fraction }\end{array}$ & $\begin{array}{c}\text { Mole } \\
\text { fraction }\end{array}$ & $\begin{array}{c}\text { Volume } \\
\text { fraction }\end{array}$ \\
\hline $\mathrm{CO}_{2}$ & 0.0000 & 0.0000 & 0.0000 \\
\hline $\mathrm{N}_{2}$ & 0.0000 & 0.0000 & 0.0000 \\
\hline $\mathrm{C} 1$ & 0.0000 & 0.0000 & 0.0000 \\
\hline $\mathrm{C} 2$ & 0.0000 & 0.0000 & 0.0000 \\
\hline $\mathrm{C} 3$ & 0.0002 & 0.0009 & 0.0003 \\
\hline $\mathrm{i}-\mathrm{C} 4$ & 0.0003 & 0.0012 & 0.0005 \\
\hline $\mathrm{n}-\mathrm{C} 4$ & 0.0018 & 0.0070 & 0.0026 \\
\hline $\mathrm{i}-\mathrm{C} 5$ & 0.0028 & 0.0086 & 0.0040 \\
\hline $\mathrm{n}-\mathrm{C} 5$ & 0.0054 & 0.0165 & 0.0075 \\
\hline $\mathrm{C} 6$ & 0.0163 & 0.0427 & 0.0206 \\
\hline $\mathrm{C} 7+$ & 0.9732 & 0.9231 & 0.9646 \\
\hline
\end{tabular}

\subsection{Experimental method}

Sample Preparation and Basic Sample Characterization. 7 full sized cylindrical core samples ('cores') of 1.5" (38.1 $\mathrm{mm}$ ) diameter and 2" (50 $\mathrm{mm})$ lengths, and $5 \mathrm{~mm}$ length end pieces from both ends (top and bottom, 14 in total) were drilled out from a single block. The cores and end pieces were sonicated to remove fines and then dried at $90^{\circ} \mathrm{C}$ for two days. Then the dry weight of the cores was measured before being vacuumed and saturated by $\mathrm{NaCl}$ brine for wet weight measurements. The saturation porosity could then be estimated (the porosity of the end pieces was assumed to be the same). The 7 cores were mounted in flow-cells and the brine-permeability was estimated from differential pressure measurements and Darcy's law. The saturation porosity and brine permeability estimates are given in Table 4.

Table 4. Experimental measurements for Kansas chalk

\begin{tabular}{|c|c|c|c|c|c|c|c|c|}
\hline $\begin{array}{c}\text { Core } \\
\text { No. }\end{array}$ & $\begin{array}{c}\text { Sat. porosity } \\
(\%)\end{array}$ & $\begin{array}{c}\text { Brine Permeability } \\
(\mathrm{mD})\end{array}$ & $\begin{array}{c}\text { Aging Time } \\
(\text { days })\end{array}$ & $\begin{array}{c}\boldsymbol{S}_{\boldsymbol{w i}} \\
(\boldsymbol{\%})\end{array}$ & $\begin{array}{c}\boldsymbol{S}_{\boldsymbol{o r}} \\
(\%)\end{array}$ & $\begin{array}{c}\text { Contact Angle } \\
\left({ }^{(}\right)^{*}\end{array}$ & $\begin{array}{c}\text { SEM-MLA } \\
\text { oil } \%\end{array}$ & $\begin{array}{c}\boldsymbol{I}_{\boldsymbol{w}} \\
(\text { USBM })\end{array}$ \\
\hline 1 & 38.57 & 2.10 & 6 & 64.71 & 19.23 & $65(29.4)$ & 10 & 0.368 \\
\hline 2 & 38.49 & 1.90 & 9 & 54.32 & 13.82 & $66(26.8)$ & 19 & 0.510 \\
\hline 3 & 37.76 & 2.01 & 12 & 58.10 & 6.10 & $78(9.1)$ & 27 & 0.005 \\
\hline 4 & 36.93 & 1.92 & 15 & 62.61 & 8.81 & $85(7.5)$ & 37 & 0.053 \\
\hline 5 & 38.04 & 1.96 & 18 & 54.15 & 4.13 & $102(6.2)$ & 37 & 0.864 \\
\hline 6 & 38.06 & 2.00 & 21 & 54.33 & 4.28 & $110(4.2)$ & 39 & -0.018 \\
\hline 7 & 37.63 & 1.95 & 30 & 58.64 & 2.15 & $108(4.5)$ & 46 & -0.165 \\
\hline
\end{tabular}


Centrifuge for Primary Drainage. The 7 brine saturated cores including the 14 top and bottom end pieces with filter paper in between, were mounted into the core holders of the centrifuge (Rotosilenta 630RS centrifuge from Vinci Technologies). An overburden/confining pressure of $200 \mathrm{psi}(1.38 \mathrm{MPa})$ was used, and the centrifuge was operated in drainage mode to displace the brine with oil to irreducible water saturation. Drainage was performed in 7 steps from $500 \mathrm{rpm}$ to $3500 \mathrm{rpm}$ in increments of $500 \mathrm{rpm}$ with 3 hours of equilibration time for each step. The capillary pressure was calculated at any position, $r$, along the core length using the HasslerBrunner equation [15]:

$$
P_{c}(r)=\frac{1}{2} \Delta \rho \omega^{2}\left(r_{1}^{2}-r^{2}\right)
$$

where $\Delta \rho=\rho_{\text {out }}-\rho_{\text {in }}$ is the density difference between the fluid expelled from the core $\left(\rho_{\text {out }}\right)$ and the fluid entering the core $\left(\rho_{i n}\right), \omega$ is the angular rotation speed of the centrifuge, and $r_{1} \simeq 22.1 \mathrm{~cm}$ (for drainage mode of centrifuge) and $16.5 \mathrm{~cm}$ (for imbibition mode of centrifuge) and $r$ (varying from 0 to $5 \mathrm{~cm}$ ) are the distances from the rotational axis to the outlet face and any point along the core length, respectively. In addition Table 4).

After aging, the 7 full sized cores were used for USBM wettability measurement, and the 7 top and 7 bottom end pieces were used for the contact angle measurements and SEM-MLA analyses, respectively.

Wettability determination by USBM of cores. After the primary drainage (oil displaced brine) and aging, the $\mathrm{NaCl}$ brine was forcibly imbibed (primary imbibition) into the cores using the centrifuge in imbibition mode to obtain residual oil saturation $S_{\text {or }}$ - before a secondary drainage (oil displaced brine) was performed to reach the irreducible water saturation, as described by McPhee et al. [16]. The receiving tubes coupling cups to core holders, were saturated by the same fluid as the cups holding the fluid that enters the cores. A confining pressure of $200 \mathrm{psi}$ and 7 centrifugal steps from 500 to $3500 \mathrm{rpm}$ at $500 \mathrm{rpm}$ increments for 3 hours equilibration time was used. Areas

) was used as the droplet fluid and each droplet was of size $\sim 5 \cdot 10^{-4} \mathrm{ml}$ (radius of $0.5 \mathrm{~mm}$ ). The sessile drop method uses a contact angle goniometer, which allows the user to measure the contact using digital photography for immobile and permanently attached droplets placed by a syringe onto the chalk end piece surface. 8-10 photographs were acquired over 2 minutes each enabling us to observe how the droplet obtained a stable geometry over time. The contact angle measurement was done on trimmings that were on top of the consolidated sample. These trimmings were at the oil front during the primary imbibition process. Hence it was assured that the saturation was uniform. Contact angle was measured at multiple spots (about 10 to 12) on the surface of the trimming and an average value was taken as the contact angle for that particular samples resulting in 150 to 300 data points for each sample. Initially brine drops were left to Hassler Brunner method, Forbes and Forbes-splines method were also applied, but there was no significant improvement in the model fit. According to Forbes [16] It is assumed that the pressure field in the core is linear, (neither radial nor centrifugal), and gravity is neglected. These assumptions can be satisfied for very short and narrow samples spun far from the rotation axis. In the case of Vinci centrifuge, the geometry is such that (sample being far from the rotation axis), the pressure field in the core is almost linear which is not the case with other centrifuge's (Beckmans). Hence this was determined to be reason for very little difference between the results of Hassler Brunner and Forbes equations in our case.

After reaching an equilibrium between the oil/water saturation and capillary pressure, hence when no more brine is being produced, the brine expelled from the core was measured and the average water saturation for each rotation speed was obtained. This water saturation (\%) was plotted against the capillary pressure estimated from equation (1) to produce the capillary pressure curve.

Aging. After the centrifuge the confining pressure was reduced to $100 \mathrm{psi}$ and then the core holders with cores and end pieces inside were placed in the oven to age at $90^{\circ} \mathrm{C}$ for aging time ranging from 6 to 30 days (

under the secondary drainage curve $\left(A_{1}\right)$ and primary imbibition curve $\left(A_{2}\right)$, when plotting the capillary pressure against water saturation enabled us to estimate the wettability index $I_{w}$ via:

$$
I_{w}=\log \left(A_{1} / A_{2}\right)
$$

The trapezoidal method was used to estimate the area under the curves. In conjunction to the formula above, the wettability index $I_{w}$ is greater than 0 for water wet, smaller than 0 for oil wet and around 0 for neutral wet systems.

Wettability determination by Contact Angle Measurements of the top end pieces. The top end piece of the aged core sample was mounted in a Vinci IFT 700 instrument to measure the contact angle by sessile drop method. The same $\mathrm{NaCl}$ brine (

for a longer duration to observe the change in contact angle, but this largely due to evaporation of the brine droplet. Also, leaving the brine droplet for a longer duration resulted in formation of salt crystals on the surface causing discrepancies in the contact angle measurements. Hence, contact angle measurement at multiple spots on the rock surface was performed an average value of the contact angle measurement is reported. On the other hand it was understood that roughness will impact contact angle measurements. It is understood that the contact angles measured are effective and will vary depending on surface treatment. But in this case all samples were treatment the same way and that the contact angles can be compared. All the sample trimmings were cut with the same saw using SS blade (1/16"). The chalk samples that were used for contact angle and SEMMLA were also cut in the same way. We don't believe the 
surface roughness influenced the contact angle measurement within our measurements as the shape of the droplet did not change from sample to sample or within a sample.

Wettability determination by SEM-MLA analysis of the bottom end pieces. In the last stage, the bottom end piece of the aged core sample was used for SEM-MLA analysis [10]. A FEI Quanta 650 FEG SEM, equipped with Bruker high throughput Energy Dispersive X-ray (EDX) system and backscattered electron detectors was used for this purpose. Imaging of the flat sample surfaces was carried out at very low vacuum conditions ( 0.6 Torr) [17]. Additionally, the end pieces were not subjected to any metallic or carbon coating on the surface, which is a standard procedure for SEM-MLA analysis, except for liquid graphite coating on the sample holder. The instrument conditions and parameters were: high voltage of $25 \mathrm{kV}$, spot size of 5.75 , working distance of $13.5 \mathrm{~mm}$, $10 \mathrm{nA}$ beam current, $16 \mu \mathrm{s}$ BSE dwell time, 10-pixel minimum size (400-pixel frame resolution for $1 \mathrm{~mm}$ High Full Well (HFW) capacity), and $12 \mathrm{~ms}$ spectrum dwell for EDX. The MLA acquisitions were performed using the 3.1.4.683 $\mathrm{MLA}^{\mathrm{TM}}$ software and each acquisition took between 3 and 4 hours per sample. Minerals and fluids in the core sample were calculated through a custom classification script that accounted for porosity and mineralogy. The results for individual samples were acquired as a digital map of the minerals and a data table listing their mineral composition. Prior to testing the individual aged end pieces, two pure chalk pieces; one with a drop of the oil mixture and another with a drop of 1.1 M NaCl-brine on it, were analyzed to determine the oil and $\mathrm{NaCl}$-brine (termed 'halite') signature and added to the SEM mineral database. The aged end pieces were then analyzed to determine the relative quantity of oil, halite and carbonate in percent. The premise is to link the oil/halite concentrations to the overall wetness of the mineral surface, which in this study is controlled by the aging time.

\section{Results and discussion}

The premise of this work was to measure wettability of aged Kansas chalk using three techniques at varying aging time while keeping brine and oil composition, and aging temperature fixed.

Before aging, the samples were brought to irreducible water saturation $\left(S_{w i}\right)$ using the primary drainage method. From trial and error, it was found that a confining pressure of $200 \mathrm{psi}(1.38 \mathrm{MPa})$ was optimal to avoid disintegration of the cores during centrifuge tests. The irreducible water saturation was found to be 54.15 to $64.71 \%$ for all cores (Table 4). The dilution evaporation method proposed by Springer (XX) demonstrated saturation levels down to $1 \%$. But the evaporation technique is limited to drainage process using only fluid (brine) and becomes irrelevant involving multiple fluids e.g oil and brine or to complete the multiple drainage and imbibition cylcle for wettability estimation.

After the samples were aged they were imbibed by $\mathrm{NaCl}$ brine (primary imbibition) from $S_{w i}$ to the residual oil saturation (Sor, see Figure 1 and Table 4). The area under the $P_{c}$ vs $S_{w}$ curve during primary imbibition is termed $A_{2}$. Then, the cores were taken out of the holders which were switched to drainage mode before secondary drainage was performed (in which oil expelled brine). The area spanned by the $P_{c}$ vs $S_{w}$ curve is termed $A_{1}$.

The wettability index $I_{w}$ from USBM method was estimated using the $\log 10$ of the ratio $A_{1}$ by $A_{2}$ in equation (2). From the WI reported in Table 4, it can be seen that, except from chalk number 5 (18 days), an increasing aging time leads to a lowered wettability index, ranging from 0.36 and 0.51 for 6 and 9 days aging to around zero for 12,15 and 21 days, and -0.15 for 30 days aging. Figure 2 (left) gives a plot of wettability index estimated by USBM method as a function of aging time. The abnormality with result from sample aged 18 days is quite uncertain. But during the USBM tests it was observed that number of tests have to be repeated as the samples disintegrated due to excess overburden pressure. This resulted in additional tests to optimize the confining pressure required for successful drainage and imbibition tests on the samples. Even though the confining pressure was optimized by trial and error, and the confining pressure used for the sample with 18 days aging time is the same as the other samples, we suspect that this outlier may have been caused by natural fractures present in chalk which led to further disintegration during the primary imbibition and secondary drainage that was not visible during the initial tests.

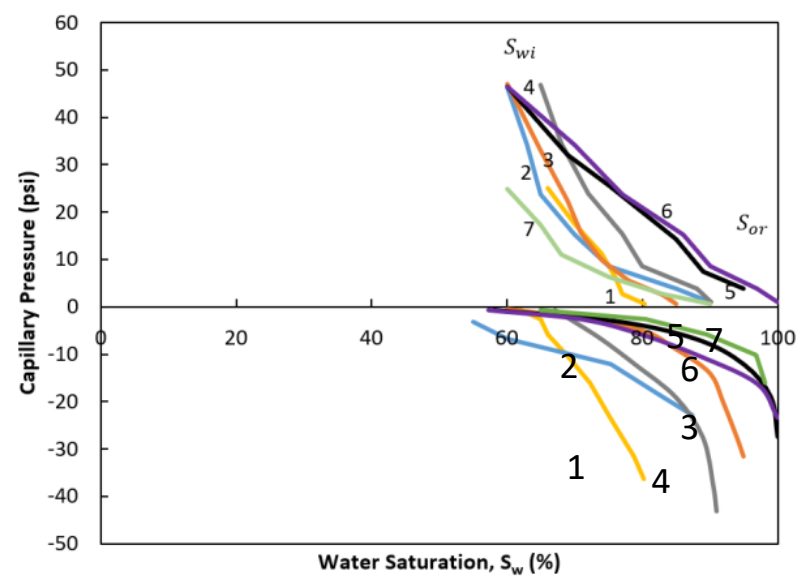

Fig. 1. Primary imbibition (brine displacing oil, $P_{c}<0$ ) and secondary drainage (oil displacing brine, $P_{c}>0$ ) for Kansas chalk samples 1 to 7 , number of aging days in parenthesis: 1 (6yellow), 2 (9-blue), 3 (12-orange), 4 (15-grey), 5 (18-black), 6 (21-purple) and 7(30-green). Note: For samples 5 and 6, the primary imbibition data was adjusted to $100 \%$ maximum saturation as the experiments overestimated the saturations to beyond $100 \%$. The $S_{\text {or }}$ reported for samples 5 and 6 in Table 4 are assumed to be the penultimate points after the saturations were adjusted to $100 \%$.

In summary each method provided a conclusion that could not be perceived as unanimous. This discrepancy in the experimental data may have originated mainly from the USBM method. Although the data shows only 7 samples with 7 aging times, more than 30 samples were tested with almost half of them breaking apart. Initially the samples were not able to withstand the confining pressure and with 
that reduced and optimized, we had samples coming out intact in the primary drainage stage. The core samples (used for USBM) went through further damage during the primary imbibition and secondary drainage. Hence it was with great difficulty we were able to get reliable data for the USBM method. This was not the case for the trimmings used for the contact angle measurement and the SEM-MLA analysis. In these cases, the trimmings being just a few millimeters, we were able to get a saturated and a more reliable sample after few attempts. The trimmings for the SEM-MLA were selected once the primary drainage test was found to be reliable as the data was similar for all the samples. For SEM-MLA analysis, the trimmings being barely few millimeters were put though the primary drainage process and selected for aging. This again took number of attempts to eventually select the 7 samples and age them

The top end pieces were analyzed with contact angle measurement in which a brine droplet was placed on the sample. It was found impossible to place a stable droplet onto the samples aged for 6 and 9 days, as the droplet initially had a maximal contact angle of around $65^{\circ}$, but within only a few seconds, it started to spread out and got sucked into the chalk developing into a contact angle of $0^{\circ}$ in time. Hence, obtaining a stable, time independent, contact angle measurement was not possible for samples with 6 and 9 aging days. For samples aged for 12 days and 30 days the sessile droplets formed enabling stable contact angle measurements. For the 12 and 15 days samples contact angles of $78^{\circ}$ and $85^{\circ}$ were found respectively. Increasing the aging time to 18,21 and 30 days the contact angle increased to 102,110 , and $108^{\circ}$, respectively (Figure 2 (right) and Figure 3, Table 4). Hence, as the aging time is increased to 18 days and beyond, the contact angle reached a plateau of more than $100^{\circ}$ which is in-line with oil wet characteristics, said to be greater than $105^{\circ}$ $[2,4,5]$. Figure 2 (right) gives a plot of contact angle as a function of aging time.
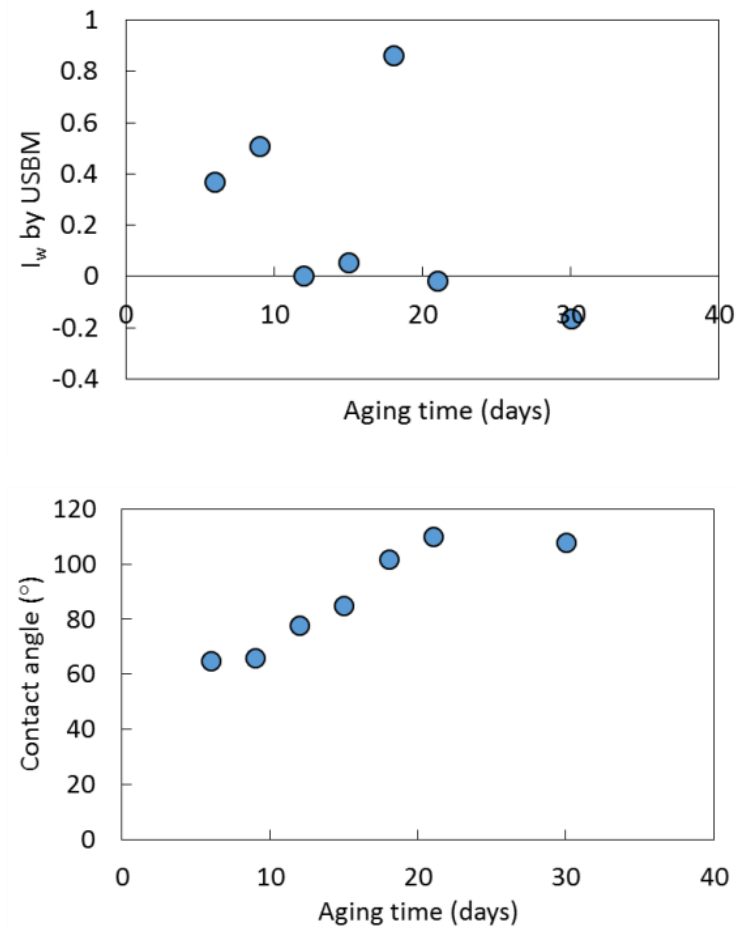

Fig. 2.Top: Wettability index measurement using USBM method as a function of aging time. Bottom: Contact angle on the top end piece of aged chalk cores as a function of aging time.

The lower end pieces were analyzed using SEMMLA in which the oil/brine content of the surface of the samples was determined (Table 5). The use of a predefined signature of the oil, calcite mineralogy and brine in the MLA-database simplified the analysis compared to a similar study using Berea sandstone [8]. Based on the individual surface measurements (reported in Table 5) for the amount of oil/brine/calcite of the aged chalk samples, we report the SEM-MLA wettability estimate in Table 4. Figure 4 provides two examples of mineral/fluid MLA maps and SEM images of samples aged for 6 days and 30 days showing how an increasing aging time results in an increased oil signature on the chalk samples. The wettability measurements reported here, from all three methods, imply that an aging time exceeding 21 days was sufficient to ensure that the Kansas chalks are oil wet when the samples were saturated by $1.1 \mathrm{M} \mathrm{NaCl}$-brine and $2.12 \mathrm{mg} \mathrm{KOH} / \mathrm{g}$ oils and aged at $90^{\circ} \mathrm{C}$.

Table 5. Mineral list from the SEM-MLA analysis for Kansas chalk samples 1 to 7, number of aging days in parenthesis: 1(6), 2(9), $3(12), 4(15), 5(18), 6(21)$ and 7(30).

\begin{tabular}{|c|c|c|c|c|c|c|c|c|}
\hline Colour & Mineral & $\begin{array}{c}\text { No. 1 } \\
\text { (Area \%) }\end{array}$ & $\begin{array}{c}\text { No. 2 } \\
\text { (Area \%) }\end{array}$ & $\begin{array}{c}\text { No. 3 } \\
\text { (Area \%) }\end{array}$ & $\begin{array}{c}\text { No. 4 } \\
\text { (Area \%) }\end{array}$ & $\begin{array}{c}\text { No. 5 } \\
\text { (Area \%) }\end{array}$ & $\begin{array}{c}\text { No. 6 } \\
\text { (Area \%) }\end{array}$ & $\begin{array}{c}\text { No. 7 } \\
\text { (Area \%) }\end{array}$ \\
\hline & Carbonate & 8 & 21 & 61 & 3 & 57 & 50 & 31 \\
\hline & Halite & 82 & 60 & 12 & 60 & 6 & 11 & 23 \\
\cline { 2 - 9 }$y$ & Oil & 10 & 19 & 27 & 37 & 37 & 39 & 46 \\
\cline { 2 - 9 } & Others & 0 & 3 & 3 & 4 & 3 & 1 & 2 \\
\hline
\end{tabular}




\section{Conclusions}

1. 7 outcrop Kansas chalk cores together with $5 \mathrm{~mm}$ thick top and bottom end pieces were acquired from the same block and their wettability were altered by aging for varying durations. The aging temperature, brine and oil compositions were kept fixed for all 7 aged samples.

2. Wettability was measured using three different methods viz. contact angle, wettability index via USBM method and oil saturation using SEM-MLA analysis.

3. USBM method: Increasing oil wet characteristics, i.e. close to zero meaning that the ratio of $A_{1}$ by $A_{2}$ equals 1 , was observed with increasing aging time from 12 days onward. The 18 days' experiment seemed to be an outlier result as it did not match the 12 and 15 days' (close to zero, positive value), and 21 and 30 days tests (close to zero, negative value). To ensure that the sample remained intact a confining pressure of 200 psi had to be used to prevent disintegration of the sample.

4. Contact angle measurement: With increasing aging time, the chalk samples indicated increasing oil wet characteristics, especially after 12 days aging and onwards. Contact angle values varied from $65^{\circ}$ (unstable readings from 6 and 9 days tests - water wet) to $110^{\circ}$ (very stable readings for 18,21 and 30 days test - oil wet).

5. The newly developed SEM-MLA method for oil/brine chalk surface determination provided a direct observation of the chemical composition of the end-pieces. An increasing amount of oil present on the samples was measured using MLA analysis. It was found that the oil fraction increased steadily from $10 \%$ to $46 \%$ when aging time was increased from 6 to 30 days. Interestingly MLA analysis on chalk samples was straight forward compared to Berea as the mineral list was limited.

6. Based upon the three presented measures, an aging time exceeding 21 days, at $90^{\circ} \mathrm{C}$ saturated by $1.1 \mathrm{M}$ $\mathrm{NaCl}$-brine and $2.12 \mathrm{mg} \mathrm{KOH} / \mathrm{g}$ oils, was sufficient to ensure that the Kansas chalks are oil wet. This conclusion was largely driven by the contact angle results indicating a wettability condition above 21 days. The USBM method indicated oil wet characteristics starting from 21 days added to the discrepancy on 18 days was forcing us to lean towards 18 days timeline to ensure oil wet characteristics. Hence a timeline of 21 days have been conclude to restore oil wet characteristics in chalk.

7. The tests can further be strengthened by varying brine salinity, aging temperature and the wettability tests broadened to include Amott tests in addition.

8. To overcome the higher residual water saturation in centrifuge testing, a combined approach using desatuation technique with porous plate method can be applied to complete the USBM analysis.
Wettaility estimates from the combined approach could shed more light on the optimum time to age tight carbonates like Kansas chalk.

\section{References}

1. Graue, A., Viksund, B.G., \& Baldwin, B.A., "Reproducible Wettability Alteration of LowPermeable Outcrop Chalk," (1999), Society of Petroleum Engineers. doi:10.2118/55904-PA

2. Anderson, W.G., "Wettability Literature Survey Part 1: Rock/Oil/Brine Interactions and the Effects of Core Handling on Wettability". Journal of Petroleum Technology, (1986) 38, 10, 1125-1144.

3. Zangiabadi, B., Korsnes, R.I., Madland, M.V., Hildebrand-Habel, T., Hiorth, A., \& Kristiansen, T.G., "Mechanical Properties of High And Lower Porosity Outcrop Chalk At Various Wetting States," (2009), Presented at Asheville 2009, the $43^{\text {rd }}$ US Rock Mechanics Symposium and $4^{\text {th }}$ US-Canada Rock Mechanics Symposium, Asheville, NC, 28 June-1 July.

4. Andersen, P.O., Ahsan, R., Evje, S., Bratteli, F., Madland, M.V., \& Hiorth, A., "A Model for BrineDependent Spontaneous Imbibition Experiments with Porous Plate," (2013), Society of Petroleum Engineers. doi:10.2118/164901-MS

5. Cuiec, L.E., Bourbiaux, B., \& Kalaydjian, F., "Oil Recovery by Imbibition in Low-Permeability Chalk," (1994), Society of Petroleum Engineers. doi:10.2118/20259-PA

6. Springer.N., Korsbech.U., \& Aage.H.K., Resistivity Index Measurement Without the Porous Plate: A Sesaturation Technique Based on Evaporated Produces Uniform Water Saturation Profiles and More Reliable Results for Tight North Sea Chalk. SCA 2003 - 38, Presented at The International Symposium of the Society of Core Analysts, Pau, France.

7. Maas.J, \& Springer. N., "Advanced Core Measurements "Best Practices" for Low Reservoir Quality Chalk." Available at https://www.scaweb.org/technology/best-practicesfor-chalk/

8. Robin, M., Combes, R., Degreve, F., \& Cuiec, L., "Wettability of Porous Media from Environmental Scanning Electron Microscopy: From Model to Reservoir Rocks”, (1997), Paper SPE-37235, Presented at the International Symposium on oilfield Chemistry, Houston, Texas, USA, 18-21 February.

9. Schmatz, J., Klaver, J., Jiang, M., \& Urai, J.L., "Nanoscale Morphology of Brine/Oil/Mineral Contacts in Connected Pores of Carbonate Reservoirs: Insights on Wettability From Cryo-BIBSEM," (2017), Society of Petroleum Engineers. doi:10.2118/180049-PA

10. Sripal, E., \& James, L.A., "Application of an Optimization Method for the Restoration of Core 
Samples for SCAL Experiments," Petrophysics, (2018) 59, 1, 72-81.

11. Hirasaki, G.J., Rohan, J.A., Dubey, S.T., \& Niko, H., "Wettability Evaluation During Restored-State Core Analysis," (1990), Paper SPE-20506, Presented at the SPE Annual Technical Conferences and Exhibition, New Orleans, Louisisana, USA, 23-26 September.

12. Henriksen, A.D., Fabricius, I.L., Borre, M.K., Korsbech, U., Theilgaard, A.T., \& Zandbergen, J.B., "Core density scanning, degree of induration and dynamic elastic moduli of Palaeogene limestone in the Copenhagen area," Quarterly Journal of Engineering Geology and Hydrogeology, (1999) 32, 107-117.

13. Voake, T., Nermoen, A., Ravnås, C., Korsnes, R.I., \& Fabricius, I.L., "The influence of temperature cycling and pore fluid on the tensile strength of chalk," Submitted for publication, (2018).

14. Warner, R., "Western European refineries and acidity in crude oil," S\&P Global Platts, (2017), Available at https://www.platts.com/IM.Platts.Content/InsightA nalysis/ IndustrySolutionPapers/SR-western- european-refineries-and-acidity-in-crude-oil.pdf [Accessed 26 April 2018].

15. Hassler, G.L., \& Brunner, E. "Measurement of capillary pressures in small core samples," Trans. AIME, (1945) 160, 114-123.

16. McPhee C., Reed, J., \& Zubizarreta, I., Core Analysis: A Best Practice Guide, Elsevier, Amsterdam, Netherlands, (2015), 64, 313-345.

17. Kumar, M., Fogden, A., Senden, T., \& Knackstedt, M.A., "Investigation of Pore-Scale Mixed Wettability," Paper SPE-129974, SPE Journal, (2012), 17, 1, 20-30. doi: 10.2118/129974-PA.

18. Frobes,P.L., 1997, Centrifuge Data Analysis Techniques: An SCA Survey on the Calculation of Drainage Capillary Pressure Curves from Centrifuge Measurements, paper SCA 1997 - 14, Presented at The International Symposium of the Society of Core Analysts, Calgary, Canada.

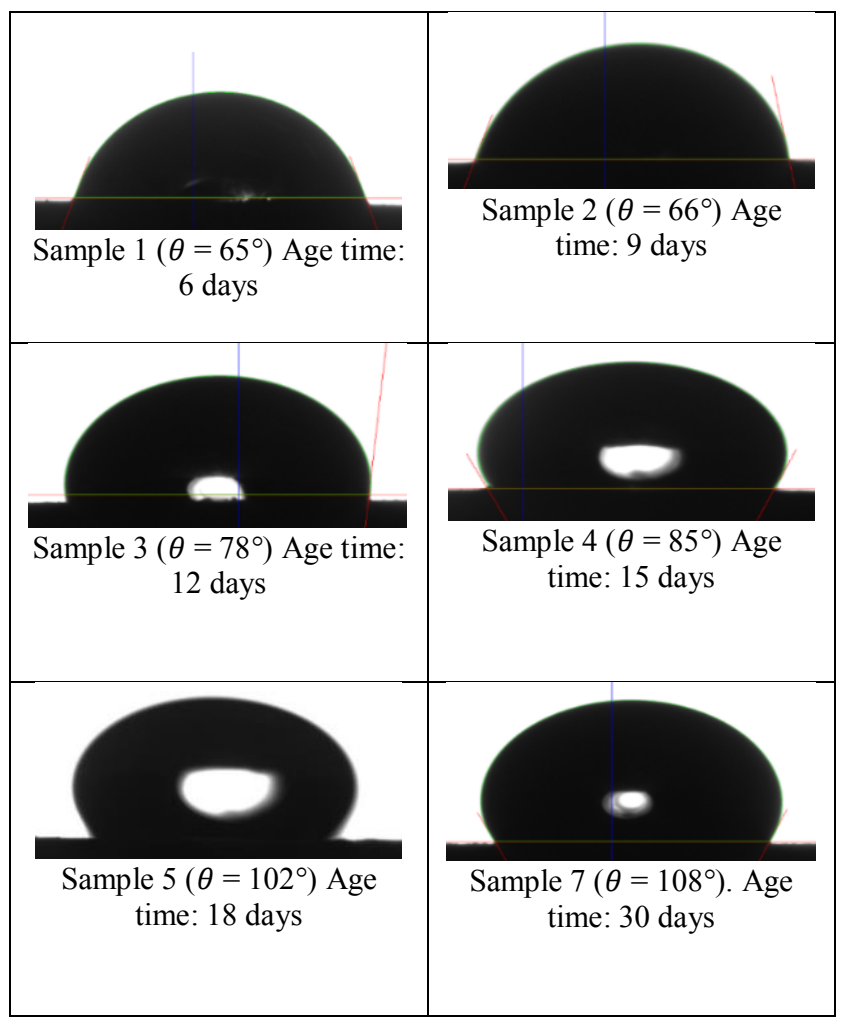

Fig. 3. Brine droplet of size $\sim 5 \cdot 10^{-4} \mathrm{ml}$ placed onto the aged top end piece. The contact angle is shown for differently aged chalk samples. 


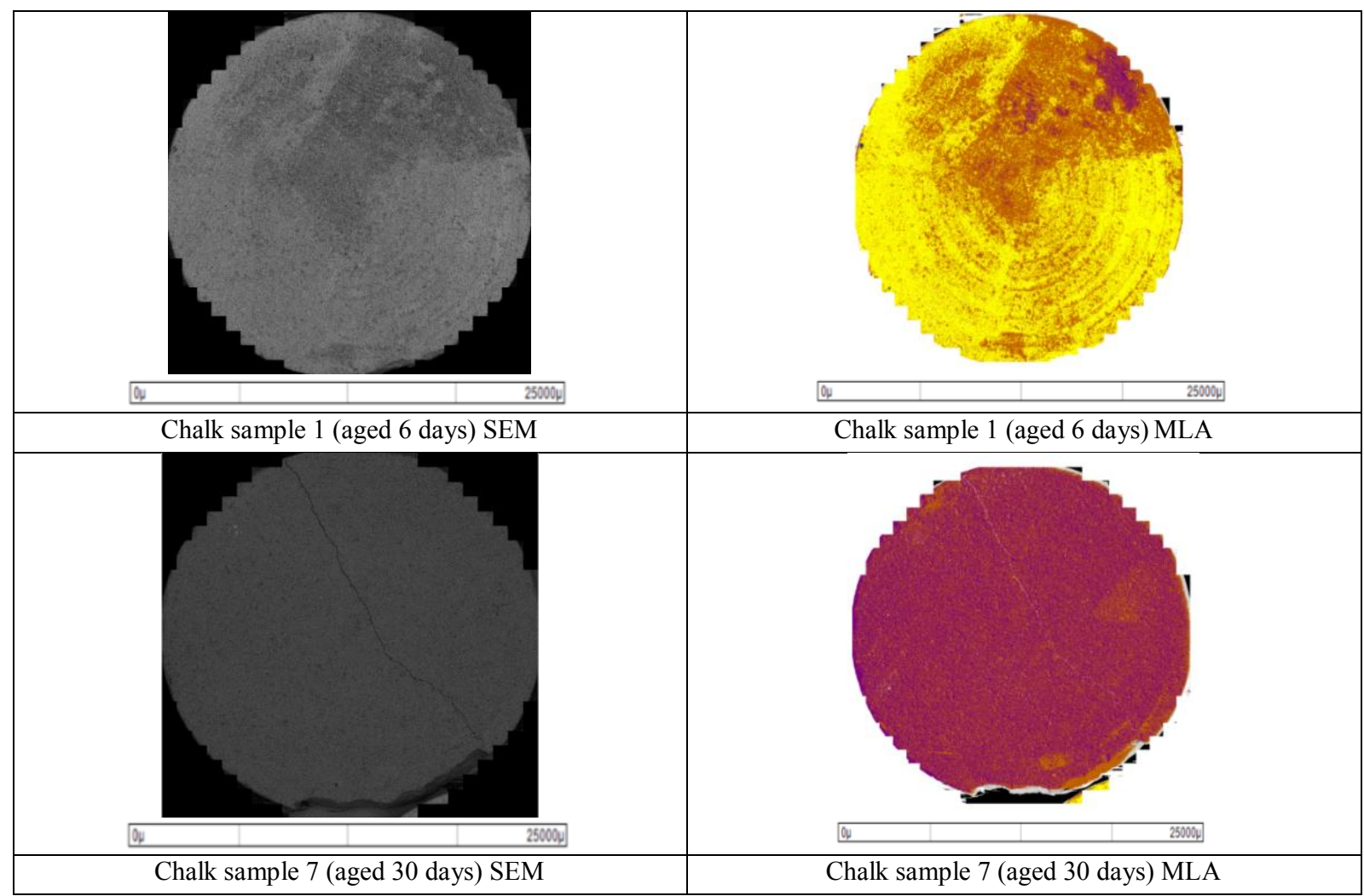

Fig. 4. SEM Images and MLA image of different aged chalk samples 